\title{
CUF, a herbal formula for the treatment of asthma: A randomized, double-blind, placebo-controlled study in the treatment of childhood asthma
}

\author{
Eliza L. Y. Wong ${ }^{1}$, Rita Y. T. Sung ${ }^{2}$, Ping-Chung Leung ${ }^{3,4^{*}}$, King-Fai Cheng ${ }^{3}$ \\ ${ }^{1}$ The Jockey Club School of Public Health and Primary Care, Faculty of Medicine, The Chinese University of Hong Kong, Hong Kong, \\ China \\ ${ }^{2}$ Department of Paediatrics, Faculty of Medicine, The Chinese University of Hong Kong, Hong Kong, China \\ ${ }^{3}$ Institute of Chinese Medicine, The Chinese University of Hong Kong, Hong Kong, China; \\ ${ }^{*}$ Corresponding Author: pingcleung@,cuhk.edu.hk \\ ${ }^{4}$ State Key Laboratory of Phytochemistry and Plant Resources in West China (CUHK), Hong Kong, China
}

Received 4 January 2013; revised 4 February 2013; accepted 5 March 2013

Copyright (C) 2013 Eliza L. Y. Wong et al. This is an open access article distributed under the Creative Commons Attribution License, which permits unrestricted use, distribution, and reproduction in any medium, provided the original work is properly cited.

\section{ABSTRACT}

Background: Complementary and alternative medicines are increasingly used for the treatment of asthma worldwide. A five-herb herbal formula (CUF) has been found to be effective and safe in an animal model of asthma and in a preliminary clinical study. Objective: The objective of this study was to evaluate the safety and efficacy of CUF in children suffering from asthma. Design: A randomized, double blind, and placebo-controlled, parallel study. Interventions: Subjects received CUF or placebo for 6 months. Efficacy variables included changes in forced vital capacity (FVC), forced expiratory volume in 1 s (FEV1), Paediatric Asthma Quality of Life Questionnaire (PAQLQ), and steroidal consumption. Results: A total of $\mathbf{1 0 0}$ asthmatic children were enrolled and assigned to two treatment groups. The first group received CUF 6 capsules ( $3 \mathrm{~g} /$ day) and the second group received placebo. There was a statistically significant difference in mean spirometric indexes in CUF group at baseline and follow-up visits. In the CUF group, the activity domain showed significant improvement $(p=0.045)$. FEV\% was significantly improved in the CUF group $(p<0.05)$ compared with the Placebo group. FEV1 also showed significant improvement after eight weeks of treatment. The requirement for steroids decreased after treatment in both groups, and no significant difference was noted between the two study groups. Conclusion: A beneficial role for CUF therapy in pediatric asthma is demon- strated. It improved the pulmonary functions of the children, namely, FEV1 and FVC. However, further research on a larger scale is warranted.

Keywords: Asthma; Children; Herbal Formula; Lung Function; Paediatric Asthma Quality of Life Questionnaire (PAQLQ)

\section{INTRODUCTION}

Asthma is a common chronic disease in childhood and its prevalence is increasing worldwide [1,2]. In Hong Kong, the prevalence of childhood asthma remained at $10 \%$ over the past 8 years [3].

Childhood asthma accounts for a significant number for hospitalizations, school absenteeism as well as interference in other daily activities [4]. It has also been associated with poor school performance, low self-image of patients, and disruption of family life $[5,6]$. Moreover, the quality of life of parents was also affected [7].

The assessment of Health-related quality of life (HRQL) has become an increasingly important issue in the management of asthma and it is often used to evaluate the effectiveness of antiasthma drugs [8].

There are several specific questionnaires for estimating the HRQL of children with asthma, which can be answered either by the children themselves or by their parents. One of the most frequently used is the Paediatric Asthma Quality of Life Questionnaire (PAQLQ), which has shown good measurement properties, proving valid and able to discriminate [9].

Modern medical therapies require daily and long-term use of asthmatic control medications that include inhalation and systemic uses of corticosteroids, leukotriene 
modifiers, long-acting $\mathrm{p} \mathrm{Z}$ agonists, theophylline and anti-IgE antibody. Glucocorticoids in large doses and long term use, may cause systemic adverse reactions. Inhalation corticosteroids are apparently safe; however, the safety is not fully understood when used on long terms. Herbal supplement may have advantages. They act on multiple targets, have wide range of effects and less drug resistance when compared with pharmaceuticals, which demand increasing doses on long-term medications [10].

The study medication (CUF) is a novel preparation containing a combination of 5 herbal extracts developed as a treatment supplement for child asthma and is prepared as a capsule. The botanical product contains $A s-$ tragalus mongholius Bunge (Huang Qi), Cordyceps sinensis Sacc (Dongcong xiacao), Radix stemonae (Baibu), Bulbus fritillariae cirrhosae (Chuanbei), and Radix scutellariae (Huang Qing). The CUF has been demonstrated to have anti-inflammatory and immunomodulatory effects in both in vitro and in vivo animal studies [11-14]. The in vitro study showed that CUF had an inhibitory effect on the allergic response by regulating the production of cytokines interleukin (IL)-4 and 6 and tumor necrosis factor-alpha (TNF-a), and by directly affecting gene expression of several key cytokines of HMC-1 $[11,14]$. The in vivo study showed that CUF has immunomodulatory effects on $\mathrm{Th} 1 / \mathrm{Th} 2$ response in ovalbumin-sensitized rats after allergen challenge and anti-inflammatory activity by reducing the eosinophils and goblet cell hyperplasia [12,13].

The main purpose of treatment in asthma is allowing the child to have a life with normal pulmonary function. Pulmonary function tests (PFTs) are used to determine asthma severity along with clinical symptoms and medication requirements. Normal lung function is one of the goals of asthma management in international guidelines, which includes forced vital capacity (FVC), forced expiratory volume in 1 second (FEV1), peak expiratory flow rate (PEFR), FEV1/FVC [15]. In this study, the researchers tried to use CUF therapy for asthma treatment. The main aim of the study was to evaluate how asthmatic children were affected by the CUF.

\section{MATERIALS AND METHODS}

\subsection{Participants}

Ninety children aged between 7 and 15 years with persistent mild-to-moderate asthma according to the Global Initiative for Asthma guideline were included in the study [16]. They were maintained on regular inhalator steroid therapy, and were able to perform reproducible spirometry tests. They were recruited in the pediatric clinics of two major government hospitals in Hong Kong.

Patients were excluded if they could not swallow cap- sules or had received parenteral or oral corticosteroids, nedocromil, cromolyn, theophylline, or anticonvulsants in the previous 4 weeks. Written informed consent was obtained from each patient and from one of their parents.

Children were considered eligible to enter the study when their asthma was active, that is when they had had symptoms, had used short-acting $\beta 2$-agonists, or had been on long-term antiasthmatic treatment during the previous year. The children's parents or guardians were requested to give their written consent prior to enrolling. Proper ethical approval was obtained from the Hospital Ethics Committee.

\subsection{HRQOL Measurements}

HRQL was assessed with the validated Chinese version of the PAQLQ.

PAQLQ has been validated and applied to the assessment of the QoL of asthmatic children in USA, Europe and some Asian countries [17-19].

\section{OBJECTIVE}

\subsection{Primary}

- To evaluate the medication score, including daily use of inhaled steroids.

- To evaluate the symptom score, including cough on daytime and nighttime, wheeze/chest tightness on daytime and nighttime, degree of shortness of breath on exertion.

\subsection{Secondary}

- To evaluate the spirometry lung function result.

- To evaluate the breakthrough attacks requiring medical attentions from $\mathrm{A} / \mathrm{E}$ doctors, family physicians or hospitalization.

- To evaluate the degree of skin allergy.

- To evaluate the changes in peripheral blood and Eosinophilic Cationic Protein (ECP).

\subsection{Study Design}

A multi-center, randomized, double blind, and placebo-controlled, parallel study. Subjects were randomized to one of the two treatment groups and treated for duration of 6 months (Figure 1).

\subsection{Quality of Life Outcome Measures}

The instrument included 23 items in three domains (activity limitation $[\mathrm{n}=5]$, symptoms $[\mathrm{n}=10]$, and emotional function $[\mathrm{n}=8]$ ). In the activity domain, three of the items were "individualized". At the first visit, the patient was asked to identify three activities that were limited because of asthma, were important to the patient and 


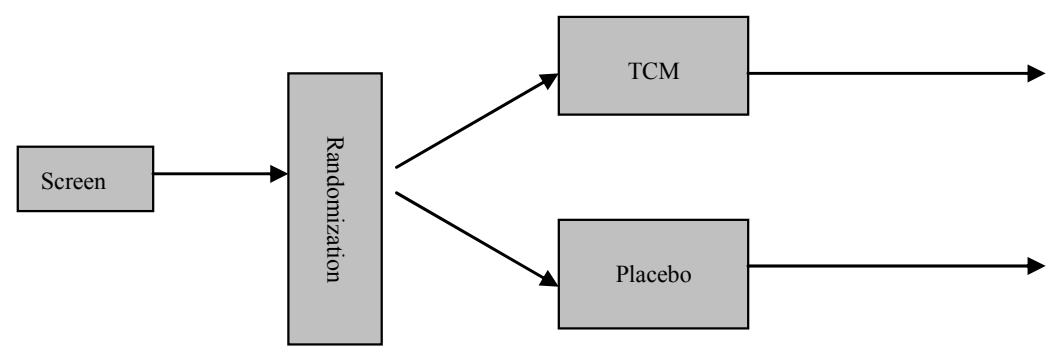

Figure 1. Study design.

were done frequently. These individualized activities were retained for each patient throughout a study. Response options for each item were on a 7-point scale where 1 indicates maximum impairment and 7 indicates no impairment. Individual items within the Paediatric Asthma Quality of Life Questionnaire were equally weighted. Results were expressed as the mean score per item for each of the domains as well as for overall quality of life. Therefore, both the domain and overall scores range from $1-7$. Patients were asked to recall impairments they had experienced during the previous week and at each follow-up visit, patients were shown the scores they recorded on their previous visit. The instrument was administered to the children without the parent being present.

A child's scores on questions belonging to each domain were summed and divided by the number of questions of the domain. Scores on all questions were summed and divided by 23, giving the overall score. Results were expressed as a mean score per item for each domain and for all 23 questions, ranging from 1 to 7 .

A change in PAQLQ score of 0.5 was considered to be clinically relevant [20].

The items are in three domains:

\begin{tabular}{|c|c|c|}
\hline $\begin{array}{l}\text { Symptoms } \\
\text { (consisting } \\
\text { of } 10 \text { items) }\end{array}$ & $\begin{array}{l}\text { Emotional } \\
\text { function (consisting of } 8 \\
\text { items) }\end{array}$ & $\begin{array}{c}\text { Activity } \\
\text { limitation } \\
\text { (consisting of } 5 \\
\text { items) }\end{array}$ \\
\hline 4 cough, & 5 frustration, & \multirow{10}{*}{$\begin{array}{c}1 \text { physical activities, } \\
2 \text { being with } \\
\text { animals, } \\
3 \text { activities with } \\
\text { frends and } \\
\text { family, } \\
19 \text { can't keep } \\
\text { up with others, } \\
22 \text { bothered in } \\
\text { activities } \\
\text { overall }\end{array}$} \\
\hline 6 tiredness, & 7 worried, & \\
\hline $\begin{array}{l}8 \text { asthma } \\
\text { attacks, }\end{array}$ & 9 angry, & \\
\hline 10 wheezing, & 11 irritable, & \\
\hline $\begin{array}{l}12 \text { tightness of } \\
\text { chest, }\end{array}$ & $\begin{array}{l}13 \text { feeling different } \\
\text { or left out, }\end{array}$ & \\
\hline $\begin{array}{l}14 \text { shortness of } \\
\text { breath, }\end{array}$ & $\begin{array}{l}15 \text { frustrated can't } \\
\text { keep up with others, }\end{array}$ & \\
\hline $\begin{array}{l}16 \text { wake up } \\
\text { during the night, }\end{array}$ & 17 uncomfortable, & \\
\hline 18 out of breath, & $\begin{array}{l}21 \text { frightened by } \\
\text { asthma attack }\end{array}$ & \\
\hline $\begin{array}{c}20 \text { trouble } \\
\text { sleeping at night }\end{array}$ & & \\
\hline 23 deep breath & & \\
\hline
\end{tabular}

\subsection{Pulmonary Function Tests}

Pulmonary function tests were performed on the baseline and follow up visits. FVC, FEV1, FEV1/FVC ratio and PEFR were recorded.

\subsection{Study Medication}

The safety of the herbal extracts was ensured after excluding heavy metals and other toxic materials before the clinical trial. The dosage for children above 12 years was set at three capsules twice daily and for children under 12 years at two capsules twice daily. Monthly supplies of the medication or the placebo were provided to the patients during the 6-month treatment period. A research nurse telephoned the family once a month between consecutive follow-up clinics in order to enforce adherence to the treatment regimen, and unused pills were counted at each visit to monitor drug compliance. Patients' diaries on the medication used would be double-checked as well.

\subsection{Manufacturing Process}

Each capsule contained $0.619 \mathrm{~g}$ of dried aqueous extract of equal weights of the five herbs. All capsules were manufactured by the Shenzhen Research Institute, Hong Kong Polytechnic University, based on Good Manufacturing Practice. The safety of the formula was ensured by the metal screening tests before the clinical trial.

\subsection{Placebo capsules}

The placebo capsules (of dark colored cornstarch) were of the same shape, color, smell, and taste with similar gelatin shell.

\section{STATISTICAL ANALYSIS}

\section{Sample Size Estimation}

To detect a $33 \%$ difference in the inhaled steroid dosage between the placebo and active groups with $80 \%$ power, 40 patients in each study group were needed. At least 80 patients were therefore recruited for this study, allowing for a $10 \%$ drop out.

The primary outcome measure was the improvement 
of quality of life and lung function test. Other outcome measures included reduction of inhalation steroids. All variables were analyzed for changes from the baseline values and for differences between the CUF2 and placebo groups. Descriptive data were expressed as mean \pm $\mathrm{SD}$. The primary outcome measure was percentage change in FEV1, FVC, FEV1/FVC and PEFR from baseline at each measured time point following treatment.

Differences in the PAQLQ and lung function parameters between the two groups were determined using repeated measures analysis of variance (ANOVA), multivariate analyses: multivariate analysis of variance (MANOVA) was carried out to assess the differences of the FVC and FEV data at all time frames. Collected data were evaluated using an analysis of covariance (ANCOVA) model, with baseline parameter included as a covariate. Paired t-test was used to compare the differences within group. Non-Parametric test such as Chi square test and Mann-Whitney test were used to compare proportions and non-normal distribution data.

All data analyses were performed using Predictive
Analytics Software/Statistical Package for the Social Sciences version 16. Two-sided tests were used and $\mathrm{p}$ values $<0.05$ were considered significant.

\section{RESULTS}

\subsection{Subject Characteristics}

A total of 112 patients were screened for enrollment, 22 of whom were excluded because of failure to meet the inclusion criteria, questionable drug compliance, time commitment, and dislike of placebo-control study design. During the treatment period, 1 patient dropped out from the CUF group and 4 patients dropped out from the placebo group. Ninety (90) patients (43 on active treatment and 47 on placebo) completed the 6-month trial period. (Figure 2) Baseline characteristics of these patients are presented in Table 1. The only significant difference between the two groups was in the body weight, which was heavier in the CUF group. Compliance was similar in the CUF and the placebo group both to the study capsules $(98 \%$ and $94 \%$, respectively, $\mathrm{p}=0.174)$ and to in-

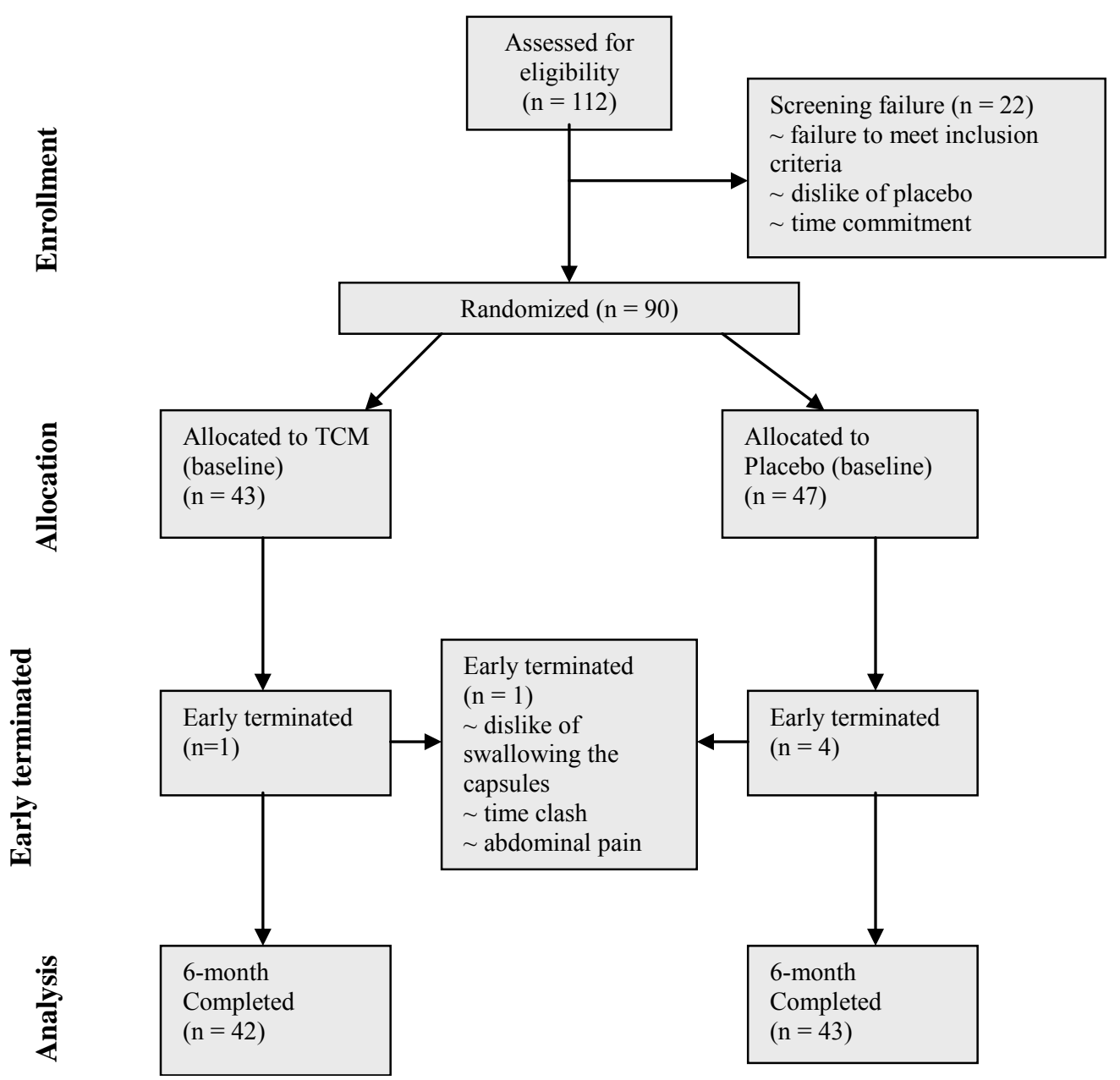

Figure 2. Disposition flowchart. 
halation steroid treatment (98\% and 95\%, respectively, $\mathrm{p}$ $=0.063$ ).

\subsection{Paediatric Asthma Quality of Life Questionnaire (PAQLQ)}

After the treatment the Overall QOL score, Symptoms and Emotions domains of both groups showed significant improvement, however, in the CUF group the Activities domain was more significantly improved $(p=0.045)$, No obvious improvement was observed in the placebo group $(\mathrm{p}=0.060)$ (Tables 2 and 3; Figure 3).

Analyzed by age group, the over 10 years group showed a better response to TCM treatment in Overall score and Symptoms domain compared with pre-treatment $(\mathrm{p}=0.019$ and $\mathrm{p}=0.018$ respectively) (Table 4, Figure 4).

\subsection{Lung Function Changes}

Before the CUF treatment, there were no significant

Table 1. Baseline characteristics of study subjects.

\begin{tabular}{|c|c|c|c|}
\hline & $\begin{array}{c}\text { TCM } \\
(n=43)\end{array}$ & $\begin{array}{l}\text { Placebo } \\
(\mathrm{n}=47)\end{array}$ & p-value \\
\hline \multicolumn{4}{|c|}{ General characteristics } \\
\hline Age (year) & $10.4 \pm 2.3$ & $10.0 \pm 2.3$ & 0.461 \\
\hline \multicolumn{4}{|l|}{ Sex } \\
\hline Male & 29 & 30 & \multirow{2}{*}{0.719} \\
\hline Female & 14 & 17 & \\
\hline Body weight $(\mathrm{kg})$ & $39.4 \pm 15.9$ & $32.6 \pm 9.0$ & 0.015 \\
\hline SBP & $106.3 \pm 13.8$ & $104.1 \pm 13.1$ & 0.450 \\
\hline DBP & $61.4 \pm 7.0$ & $61.4 \pm 7.2$ & 0.982 \\
\hline \multicolumn{4}{|l|}{ Blood chemistry } \\
\hline ТP & $74.0 \pm 4.1$ & $73.6 \pm 3.4$ & 0.570 \\
\hline ALB & $42.4 \pm 2.0$ & $42.3 \pm 1.4$ & 0.762 \\
\hline TB & $7.3 \pm 3.8$ & $8.5 \pm 7.1$ & 0.331 \\
\hline ALP & $225.7 \pm 65.0$ & $219.4 \pm 73.2$ & 0.672 \\
\hline ALT/GPT & $15.2 \pm 10.4$ & $14.5 \pm 6.2$ & 0.704 \\
\hline Creat & $56.9 \pm 18.1$ & $56.2 \pm 13.7$ & 0.842 \\
\hline Urea & $4.33 \pm 0.92$ & $4.30 \pm 0.86$ & 0.862 \\
\hline \multicolumn{4}{|l|}{$\begin{array}{l}\text { Baseline pulmonary } \\
\text { function }\end{array}$} \\
\hline FVC & $105.4 \pm 16.9$ & $103.9 \pm 14.8$ & 0.660 \\
\hline $\mathrm{FEV}_{1}$ & $96.4 \pm 15.2$ & $95.7 \pm 18.6$ & 0.860 \\
\hline $\mathrm{FEV}_{1} / \mathrm{FVC}$ & $92.1 \pm 11.0$ & $91.7 \pm 10.3$ & 0.867 \\
\hline PEFR & $91.8 \pm 17.0$ & $87.2 \pm 22.0$ & 0.280 \\
\hline
\end{tabular}

Table 2. Overall and domain score on the Paediatric Asthma Quality of Life Questionnaire (PAQLQ) of pre- and post-treatment.

\begin{tabular}{cccc}
\hline Domain & TCM & Placebo & p-value \\
\hline Overall QOL & & & \\
Pre-treatment & $6.38 \pm 0.97$ & $6.34 \pm 0.92$ & 0.812 \\
Post-treatment & $6.74 \pm 0.72$ & $6.70 \pm 0.65$ & 0.884 \\
Difference & $0.36 \pm 0.95$ & $0.38 \pm 0.97$ & 0.720 \\
p value & $\mathbf{0 . 0 1 8}$ & $\mathbf{0 . 0 1 1}$ & \\
Symptoms & & & \\
Pre-treatment & $6.34 \pm 0.99$ & $6.23 \pm 1.00$ & 0.596 \\
Post-treatment & $6.70 \pm 0.78$ & $6.65 \pm 0.69$ & 0.903 \\
Difference & $0.37 \pm 0.87$ & $0.44 \pm 1.08$ & 0.993 \\
P value & $\mathbf{0 . 0 0 8}$ & $\mathbf{0 . 0 0 8}$ & \\
Activities & & & \\
Pre-treatment & $6.28 \pm 1.21$ & $6.35 \pm 1.01$ & 0.752 \\
Post-treatment & $6.66 \pm 0.88$ & $6.68 \pm 0.73$ & 0.967 \\
Difference & $0.38 \pm 1.21$ & $0.34 \pm 1.19$ & 0.961 \\
p value & $\mathbf{0 . 0 4 5}$ & 0.060 & \\
Emotions & & & 0.8798 \\
Pre-treatment & $6.51 \pm 0.98$ & $6.47 \pm 0.90$ & 0.828 \\
Post-treatment & $6.83 \pm 0.60$ & $6.79 \pm 0.65$ & 0.798 \\
Difference & $0.33 \pm 1.06$ & $0.34 \pm 0.87$ & $\mathbf{0 . 0 1 2}$ \\
p value & 0.051 & & \\
\hline
\end{tabular}

Table 3. Overall score change during study period.

\begin{tabular}{ccrc}
\hline \multirow{2}{*}{ Group } & \multicolumn{2}{c}{ Overall PAQLQ score } & \multirow{2}{*}{ Total } \\
\cline { 2 - 3 } & \multicolumn{1}{c}{ Decrease } & Increase & \\
\hline TCM & $10(23.3 \%)$ & $33(76.7 \%)$ & 43 \\
Placebo & $15(32.6 \%)$ & $31(67.4 \%)$ & 46 \\
p value & \multicolumn{2}{c}{$\chi^{2}=0.962, \mathrm{p}=0.327$} \\
\hline
\end{tabular}

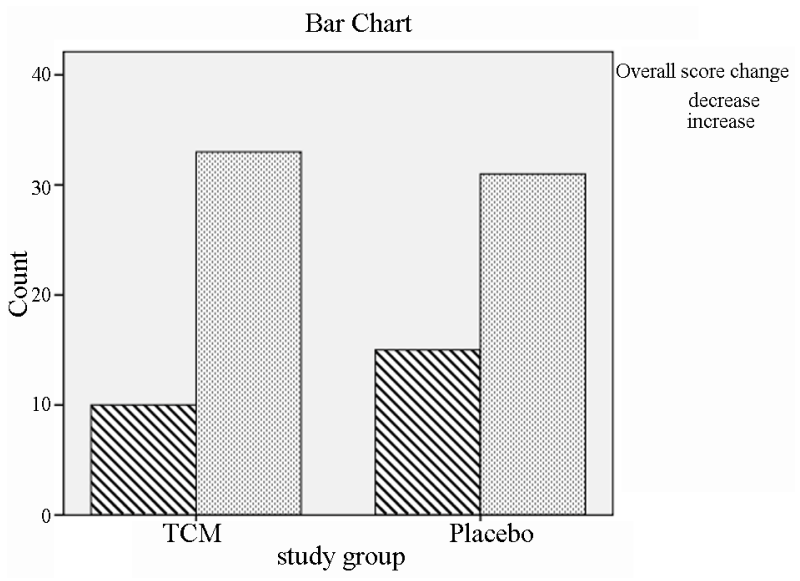

Figure 3. Overall score change during study period. 
Table 4. Age related changes in PAQLQ score.

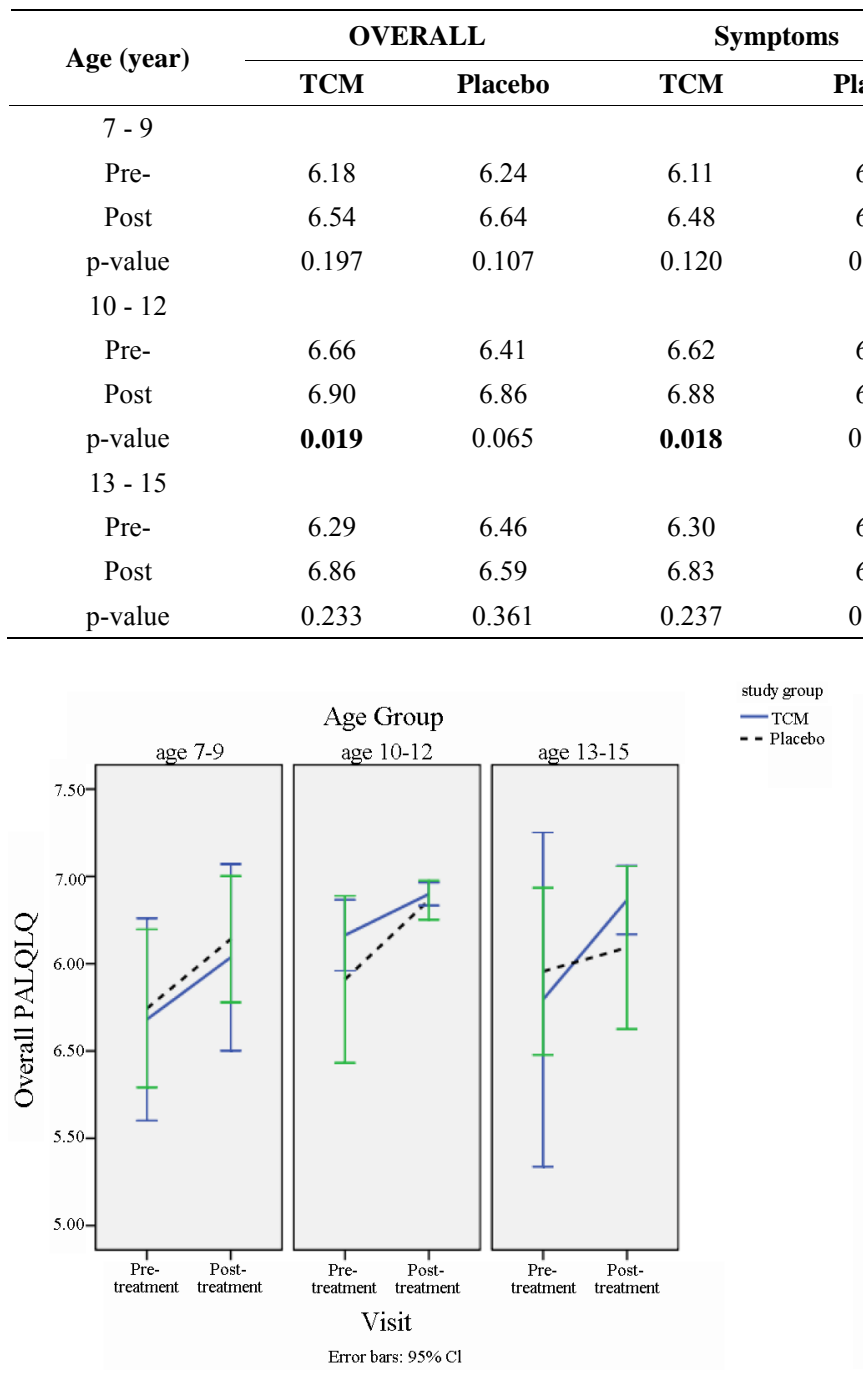

(a)

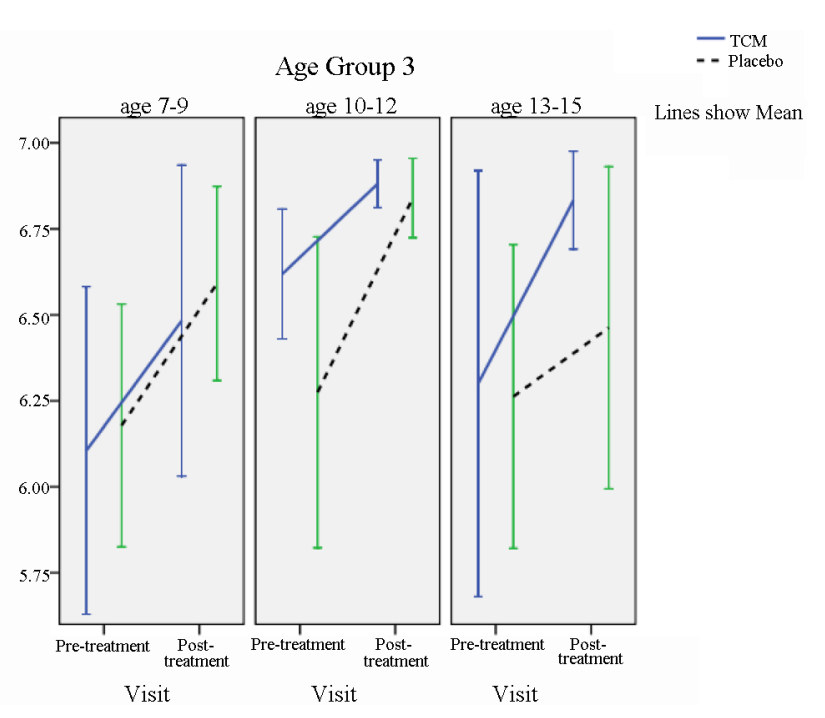

(b)

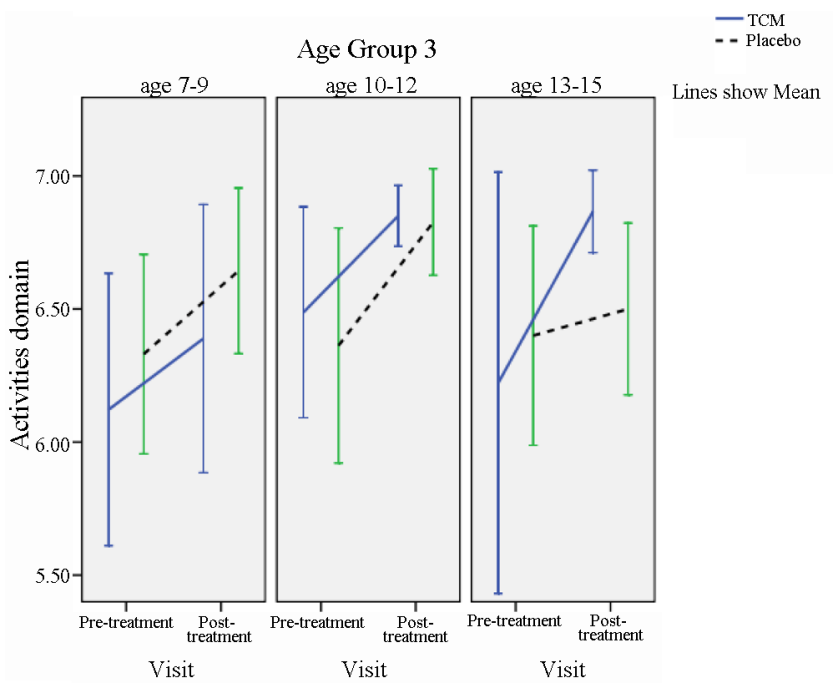

(c)

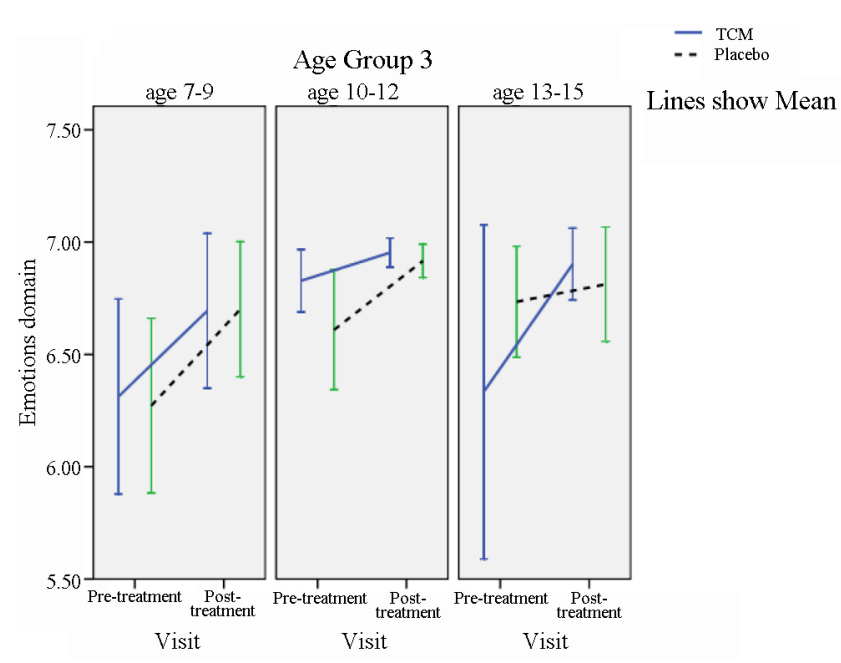

(d)

Figure 4. Overall and domain score on the Paediatric Asthma Quality of Life Questionnaire (PAQLQ) in each visit (a)-(d). 
differences in the lung function between the two groups. After eight weeks of treatment, FEV\% was significantly improved in the CUF group $(\mathrm{p}<0.05)$ compared with the Placebo group. FEV1 also showed significantly improved (Tables 5 and 6; Figures 5 and 6 ).

FVC (Forced Vital Capacity) is clinically useful as an index of lung functions. The result showed that there were significant differences in FVC between TCM and Placebo groups after treatment (Table 5, Figure 5). FVC will be diminished in both obstructive and restrictive diseases. The improvement in FVC of the children in the TCM group after treatment was significantly better than that of children in the Placebo group.

FEV1 was also showed improved after treatment and the differences between the tow groups at week 8 and week 16 were reached statistical significance (Table $\mathbf{6}$, Figure 6).

There were no significant differences between the two groups in FEV1/FVC and PEFR (Tables 7 and 8; Fig-

Table 5. Changes of lung function-FVC\%.

\begin{tabular}{cccc}
\hline & TCM & Placebo & p-value \\
\hline FVC & & & \\
Baseline(v2) & $110.6 \pm 17.3$ & $104.2 \pm 18.4$ & 0.221 \\
V3 (week 4) & $113.9 \pm 19.5$ & $103.6 \pm 20.8$ & 0.065 \\
V4 (week 8) & $106.6 \pm 20.3$ & $95.7 \pm 14.1$ & $\mathbf{0 . 0 3 8}$ \\
V5 (week 12) & $108.5 \pm 11.3$ & $97.1 \pm 13.0$ & $\mathbf{0 . 0 0 2}$ \\
V6 (week 16) & $107.7 \pm 11.9$ & $96.8 \pm 13.5$ & $\mathbf{0 . 0 0 4}$ \\
V7 (week 20) & $98.4 \pm 13.7$ & $90.6 \pm 13.6$ & $\mathbf{0 . 0 5 0}$ \\
V8 (week 24) & $95.8 \pm 12.4$ & $87.1 \pm 12.6$ & $\mathbf{0 . 0 2 5}$
\end{tabular}

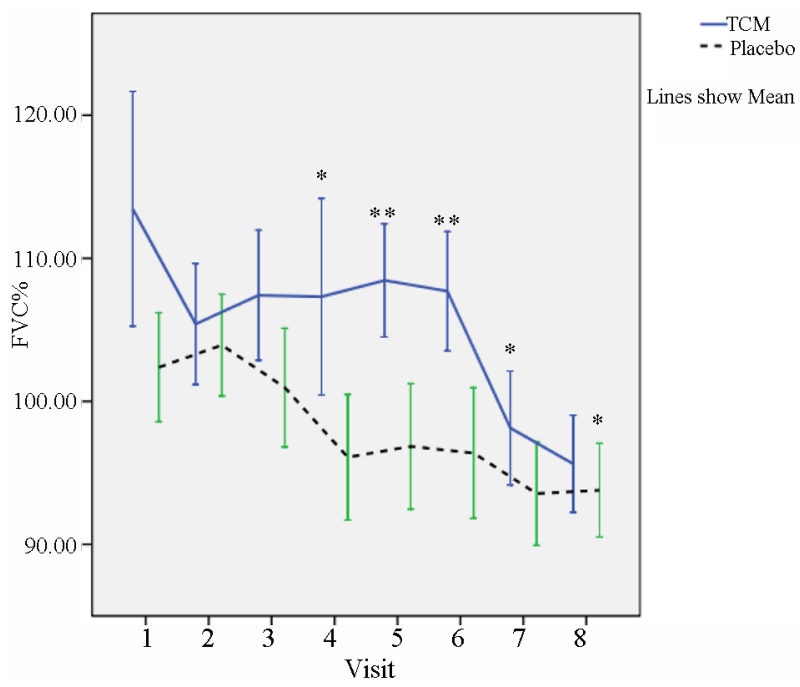

Figure 5. Changes of $\mathrm{FVC} \%$ during study period $\left({ }^{*} \mathrm{p}<0.05\right.$; $\left.{ }^{* *} \mathrm{p}<0.01\right)$. ures 7 and 8).

The requirement for steroids decreased after treatment in both groups. However, no significant difference was noted between the two study groups $(p=0.265)$ (Table 9).

\section{DISCUSSION}

Asthma is a chronic disease characterized by acute exacerbation of coughing, dyspnoea, wheezing and chest tightness. Patients usually have reduced forced expiratory volume in one second as well as reduced airflow.

This randomized double blinded placebo controlled trial compared the effects of 6 months of treatment with the encapsulated herbal mixture CUF on lung function, asthma control, Paediatric Asthma Quality of Life Questionnaire (PAQLQ), and cough related health status. It was shown that CUF therapy could improve pulmonary function. The results showed statistically significant differences in FEV1, FVC after CUF therapy compared

Table 6. Changes of lung function- $-\mathrm{FEV}_{1}$.

\begin{tabular}{cccc}
\hline & TCM & Placebo & p-value \\
\hline FEV $_{1}$ & & & \\
Baseline(v2) & $99.7 \pm 17.3$ & $93.4 \pm 22.3$ & 0.300 \\
V3 (week 4) & $101.5 \pm 24.0$ & $93.0 \pm 25.8$ & 0.260 \\
V4 (week 8) & $97.1 \pm 21.4$ & $84.5 \pm 18.9$ & $\mathbf{0 . 0 5 0}$ \\
V5 (week 12) & $94.8 \pm 12.6$ & $87.4 \pm 18.0$ & 0.121 \\
V6 (week 16) & $95.7 \pm 12.9$ & $86.6 \pm 16.8$ & $\mathbf{0 . 0 4 7}$ \\
V7 (week 20) & $87.5 \pm 15.5$ & $80.0 \pm 18.0$ & 0.136 \\
V8 (week 24) & $85.6 \pm 12.4$ & $78.2 \pm 17.7$ & 0.115 \\
\hline
\end{tabular}

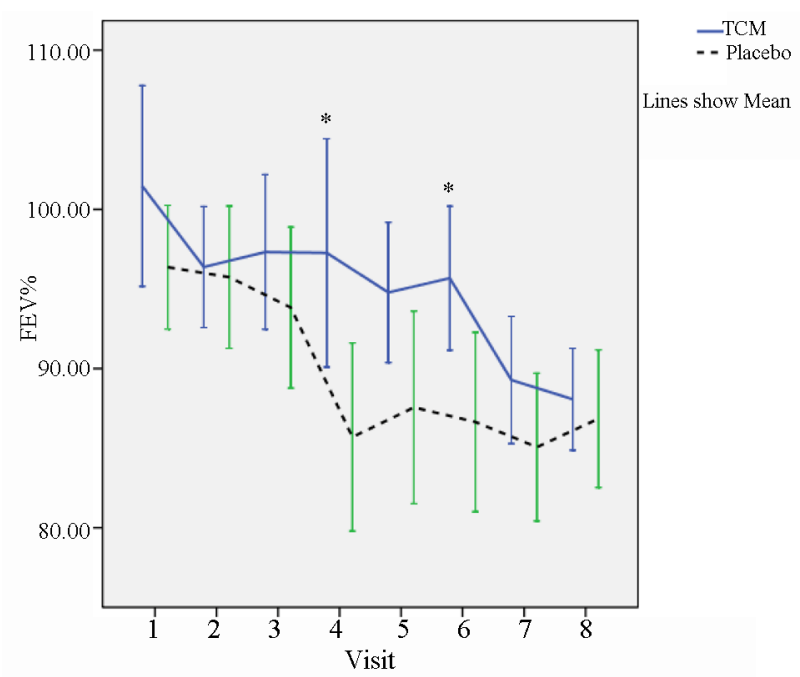

Figure 6. Changes of $\mathrm{FEV}_{1}$ during study period $\left({ }^{*} \mathrm{p}<0.05 ;{ }^{* *} \mathrm{p}\right.$ $<0.01)$. 
Table 7. Changes of lung function- $-\mathrm{FEV}_{1} / \mathrm{FVC}$.

\begin{tabular}{cccc}
\hline & TCM & Placebo & p-value \\
\hline FEV $_{1} /$ FVC & & & \\
\hline Baseline (v2) & $92.1 \pm 11.0$ & $91.7 \pm 10.3$ & 0.807 \\
V3 (week 4) & $90.9 \pm 11.8$ & $92.9 \pm 13.0$ & 0.856 \\
V4 (week 8) & $91.2 \pm 12.3$ & $89.4 \pm 11.3$ & 0.235 \\
V5 (week 12) & $87.7 \pm 10.1$ & $89.9 \pm 10.1$ & 0.420 \\
V6 (week 16) & $89.1 \pm 10.3$ & $89.5 \pm 9.8$ & 0.696 \\
V7 (week 20) & $91.4 \pm 10.4$ & $90.7 \pm 11.4$ & 0.952 \\
V8 (week 24) & $92.5 \pm 10.0$ & $92.1 \pm 10.4$ & 0.770 \\
\hline
\end{tabular}

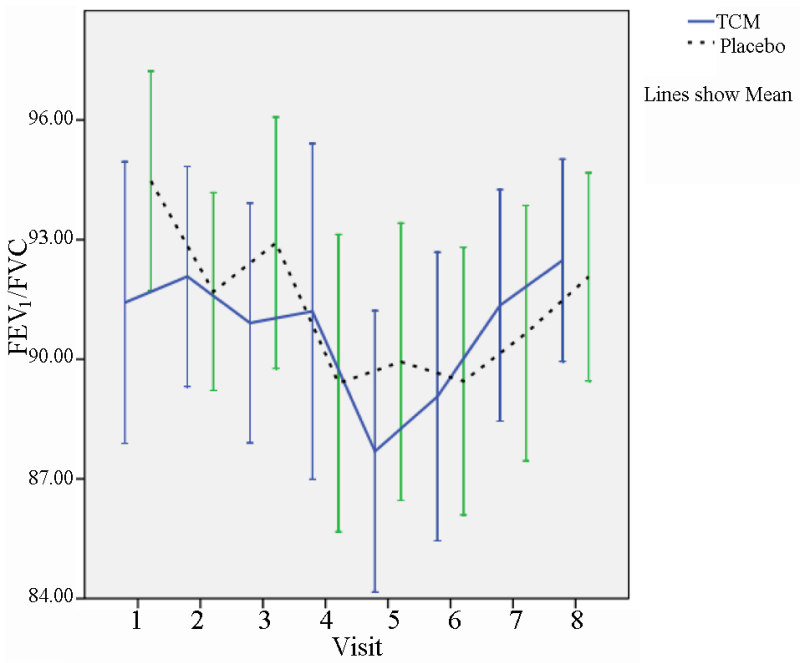

Figure 7. Changes of FEV1/FVC during study period.

with placebo group.

The primary outcome of the study was lung function. Significant improvement in lung function were found in the CUF group when compared with placebo treatment. It was therefore very likely that CUF alleviated asthmatic attacks through a direct influence on lung functions.

Prior reports suggest that complementary and alternative medicines may have some therapeutic effects on allergic asthma [21]. This study was conducted to determine the safety and efficacy of CUF for children with asthma. In the Chinese community, parents often wish to use herbal therapy to supplement conventional medical treatment for their children suffering from asthma so that the dosage of steroids could be reduced to lessen their side-effects. [22]. Our present study may have given them some assurance. CUF was safe and effective in
Table 8. Changes of lung function-PEFR.

\begin{tabular}{cccc}
\hline & TCM & Placebo & p-value \\
\hline PEFR & & & \\
\hline Baseline (v2) & $90.5 \pm 19.5$ & $82.7 \pm 24.1$ & 0.244 \\
V3 (week 4) & $87.1 \pm 30.9$ & $86.0 \pm 30.4$ & 0.907 \\
V4 (week 8) & $88.9 \pm 22.0$ & $82.2 \pm 26.6$ & 0.370 \\
V5 (week 12) & $90.5 \pm 15.7$ & $86.4 \pm 20.1$ & 0.461 \\
V6 (week 16) & $89.2 \pm 20.5$ & $83.8 \pm 17.5$ & 0.348 \\
V7 (week 20) & $85.0 \pm 16.3$ & $79.6 \pm 19.5$ & 0.324 \\
V8 (week 24) & $84.0 \pm 11.7$ & $79.2 \pm 18.8$ & 0.315 \\
\hline
\end{tabular}

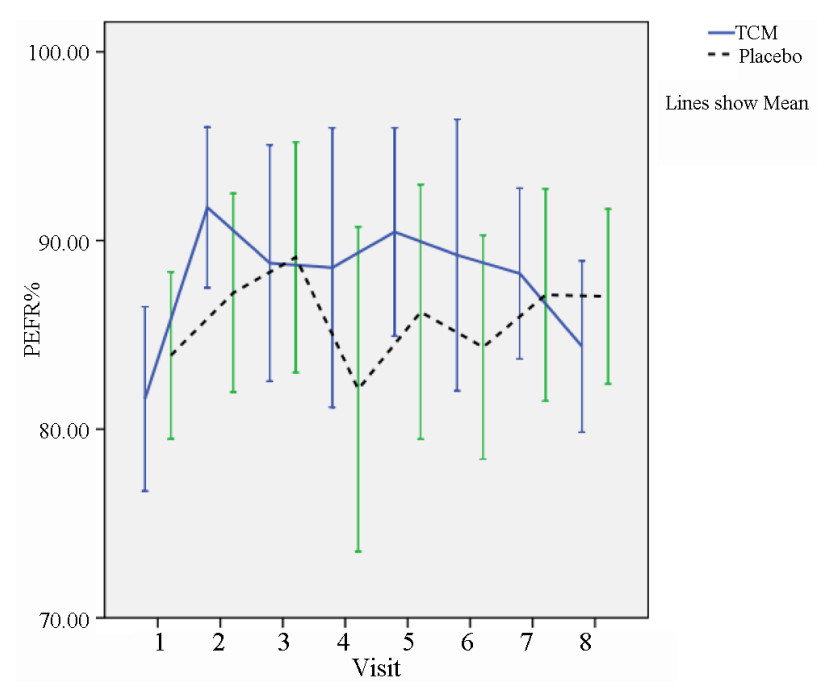

Figure 8. Changes of PEFR during study period.

improving lung functions. We chose changes in FEV1 as the first efficacy end point on account of their validity for the monitoring of airway obstruction. By the end of the study, FEV1 was significantly improved in both groups of CUF-treated patients. Moreover, a marked progression in lung function of more than 10 compared with baseline was achieved for most patients.

With the increasing popularity of herbal remedies, CUF showed a marked placebo effect. The Overall QOL score, Symptoms and Emotions domains of both groups showed significant improvement. The factors possibly contributing towards the placebo effect could be the increased nurse-patient interactions (e.g., reminder calls and monthly study visit for proper asthma management) leading to better self-cares and thus improved outcome measures.

The study did not entirely follow the approach recommended in Chinese medicine therapy: patient's "con- 
Table 9. Steroid dose change during study period.

\begin{tabular}{|c|c|c|c|c|c|c|c|}
\hline Group & Increase & Decrease & Drug type change to more severe & Drug type change to less severe & Same & Off & Total \\
\hline $\mathrm{TCM}$ & 2 & 14 & 0 & 5 & 11 & 11 & 43 \\
\hline Placebo & 1 & 12 & 2 & 4 & 7 & 21 & 47 \\
\hline P value & \multicolumn{7}{|c|}{$\chi^{2}=6.447, p=0265$} \\
\hline
\end{tabular}

stitution" and the presenting features were not specifically considered. CUF was uniformly administered throughout the course of treatment, not allowing adjustment [23]. This practice ensures a proper evaluation in the randomized controlled trial, which is essential for evidence-based research.

\section{CONCLUSION}

The results of this study showed that the CUF therapy facilitated pulmonary function. CUF therapy was better than placebo in the treatment of asthma among children. According to the clinical data, CUF might have improved airway tonicity and decreased airway sensitivity.

\section{REFERENCES}

[1] Murphy, S., Bleecker, E.R., Boushey, H., et al. (1997) Expert panel report II. Guidelines for the diagnosis and management of asthma. National Institute of Health Publication, National Asthma Education and Prevention Program, Bethesda.

[2] Sears, M.R. (1988) Epidemiology. In: Barnes, P.J., Rodger, I.W. and Thomson, N.C., Eds., Asthma. Basic Mechanisms and Clinical Management, 3rd Edition, Academic Press, San Diego, 1-33.

[3] Gary, W.K. (2005) Wong asthma epidemiology in Chinese: What have we learnt so far? Medical Bulletin, 10, 14-16.

[4] Okelo, S.O., Wu, A.W., Krishnan, J.A., Rand, C.S., Skinner, E.A. and Diette, G.B. (2004) Emotional quality-oflife and outcomes in adolescents with asthma. Journal of Pediatrics, 145, 523-529.

http://dx.doi.org/10.1016/j.jpeds.2004.06.043

[5] Goeman, D.P., Aroni, R.A., Stewart, K., et al. (2002) Patients views of the burden of asthma: a qualitative study. Medical Journal of Australia, 177, 295-299.

[6] Gustafsson, D., Olofsson, N., Andersson, F., Lindberg, B. and Schollin, J. (2002) Effect of asthma in childhood on psychosocial problems in the family. Journal of Psychosomatic Research, 53, 1071-1075. http://dx.doi.org/10.1016/S0022-3999(02)00340-9

[7] Osman, L.M., Baxter-Jones, A.D.G. and Helms, P.J. (2001) Parents quality of life and respiratory symptoms in young children with mild wheeze. European Respiratory Journal, 17, 254-258. http://dx.doi.org/10.1183/09031936.01.17202540

[8] Juniper, E.F., Guyatt, G.H., Epstein, R.S., Ferrie, P.J., Jaeschke, R. and Hiller, T.K. (1992) Evaluation of impair- ment of health related quality of life in asthma: Development of a questionnaire for use in clinical trials. Thorax, 47, 76-83. http://dx.doi.org/10.1136/thx.47.2.76

[9] Juniper, E.F., Guyatt, G.H., Feeny, D.H., Ferrie, P.J., Griffith, L.E. and Townsend, M. (1996) Measuring quality of life in children with asthma. Quality of Life Research, 5, 35-46. http://dx.doi.org/10.1007/BF00435967

[10] Zhang, J. and Guo, L.-F. (2008) Understanding and thinking about the topical treatment of asthma in children. Journal of Pediatrics of TCM, 3, 6-8.

[11] Lee, S.K.W., Wong, C.K., Sung, R.Y.T., et al. (2006) In vitro anti-allergic activities of a newly concocted traditional Chinese medicine: The wheeze-relief formula. Journal of Ethnopharmacology, 103, 406-412. http://dx.doi.org/10.1016/j.jep.2005.08.031

[12] Sung, R., Wong, Y., Chan, W., et al. (2005) Lung inflammation, goblet cell hyperplasia, cytokine and chemokine production are reduced by a Chinese herbal formulation in a rat model of asthma. Journal of Allergy and Clinical Immunology, 119, $\mathrm{S} 10$. http://dx.doi.org/10.1016/j.jaci.2004.12.053

[13] Wong, Y., Sung, R., Li, K., et al. (2006) The Chinese herbal formula CUF2 modulates Th1=Th2 responses in a rat model of allergic asthma. Journal of Allergy and Clinical Immunology, 117, 277. http://dx.doi.org/10.1016/j.jaci.2005.12.1147

[14] Wong, Y., Sung, R., Li, K., et al. (2007) Effects of the Chinese herbal formula CUF2 on cytokine release from human mast cell line. Journal of Allergy and Clinical Immunology, 119, 213. http://dx.doi.org/10.1016/j.jaci.2006.12.203

[15] Beydon, N., Pin, I., Matran, R. and Chaussain, M. (2003) Pulmonary function tests in preschool children with asthma. A American Journal of Respiratory and Critical Care Medicine, 168, 640-670. http://dx.doi.org/10.1164/rccm.200303-449OC

[16] Global Initiative for Asthma (2002) Global strategy for asthma management and prevention. NHLB=WHO Workshop Report. National Institutes of Health, National Heart, Lung and Blood Institute, Bethesda.

[17] Juniper, E.F., Guyatt, G.H., Feeny, D.H., Ferrie, P.J., Grith, L.E. and Townsend, M. (1996) Measuring quality of life in children with asthma. Quality of Life Research, 5, 3546. http://dx.doi.org/10.1007/BF00435967

[18] Sanjuas, C., Alonso, J., Ferrer, M., Curull, V., Broquetas, J.M. and Anto, J.M. (2001) Adaptation of the asthma quality of life questionnaire to a second language preserves its critical properties: The Spanish version. Journal of Clinical Epidemiology, 54, 182-189, http://dx.doi.org/10.1016/S0895-4356(00)00297-3

[19] Elizabeth, C., Suzanna, S., Tim, C.F., Chi, S.L., Mital, R. 
and Bee-Wah, L. (1999) Pediatric asthma quality of life questionnaire: Validation in children from Singapore. Asian Pacific Journal of Allergy and Immunology, 17, 155-161.

[20] Pljaskić-Kamenov, S.S., Djordjević, D.V., Radić, S.S. and Kamenov, B.A. (2002) Asthma quality of life as a marker of disease severity and treatment evaluation in school children. Medicine and Biology, 9, 175-180.

[21] Li, X.M. (2007) Traditional Chinese herbal remedies for asthma and food allergy. Journal of Allergy and Clinical Immunology, 120, 25-31.

http://dx.doi.org/10.1016/j.jaci.2007.04.030

[22] Ernst E. (1998) Use of unconventional therapies in childhood asthma. Pediatric Allergy and Immunology, 12, 2932. http://dx.doi.org/10.1089/pai.1998.12.29

[23] Tam, K. (1998) Theory of Chinese medicine. Cheng Chung Book Co., Taipei. 